\title{
PREDISPOSITION TO AUTOIMMUNE THYROIDITIS IN RING CHROMOSOME 18 SYNDROME
}

\author{
Yoshimitsu Fukushima, ${ }^{1}$ Tetsuo Fukuda, ${ }^{1}$ Yoshikazu Kuroki, ${ }^{1}$ \\ Norio Nitkawa, ${ }^{2}$ Nobuo Matsuura, ${ }^{2}$ Yutaka Yamada, ${ }^{3}$ \\ and Atsushi Ieshima ${ }^{4}$ \\ ${ }^{1}$ Division of Medical Genetics, Kanagawa Children's Medical Center, \\ 2-138-4, Mutsukawa, Minami-ku, Yokohama 232, Japan \\ ${ }^{2}$ Department of Pediatrics, Hokkaido University School of Medicine, \\ $N-15, W-7$, Kita-ku, Sapporo 060, Japan \\ ${ }^{3}$ Pediatric Clinic, Hakodate Chuo Hospital, 33-2, Hon-cho, \\ Hakodate 040, Japan \\ ${ }^{4}$ Division of Child Neurology, Institute of Neurologic Science, \\ Tottori University School of Medicine, 86 Nishi-machi, \\ Yonago 683, Japan
}

\begin{abstract}
Summary Thyroid function was studied in five patients with ring chromosome $18[\mathrm{r}(18)]$ syndrome and in their mothers. Three of the five patients were clinically or subclinically hypothyroid and had an elevated anti-thyroid antibody (ATA) titer. Another patient had a goiter with the histology showing Hashimoto's thyroiditis. Two mothers of the five patients had an elevated ATA titer, one of whom was subclinically hypothyroid. Our findings indicate that autoimmune thyroiditis may occur with high frequency among patients with $\mathrm{r}(18)$ syndrome and their mothers. Thus thyroid function tests are always recommended in patients with the syndrome and their mothers.
\end{abstract}

\section{INTRODUCTION}

Susceptibility to thyroid diseases in a patient with an abnormality of chromosome 18 , especially with $18 \mathrm{p}$ - syndrome, has been repeatedly reported (Bühler et al., 1964; Ruvalcava, 1970; Malpuech et al., 1971; Faed et al., 1972; Kistenmacher et al., 1973; Hasen and Bartalos, 1975; Gluckman, 1977; Jones and Carey, 1982). Among the chromosome 18 abnormalities, ring chromosome 18 [ $\mathrm{r}(18)]$ syndrome is relatively rare, and there has been only a patient in which both $r(18)$ syndrome and hypothyroidism were observed (Winter et al., 1972).

An encounter with a patient with $\mathrm{r}(18)$ syndrome (Case 1) suffering from hypo-

Received January 13, 1984; revised version received April 23, 1984 


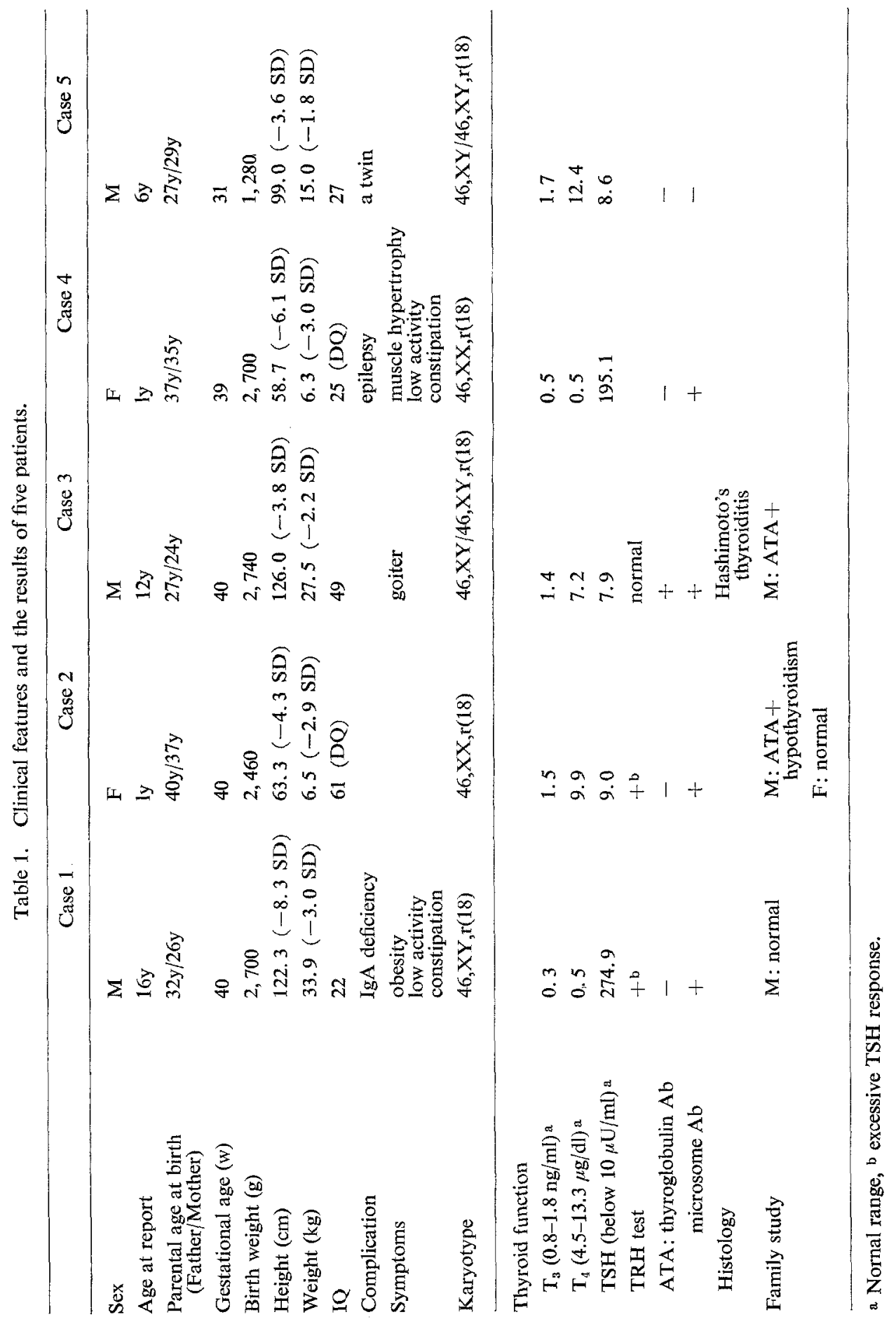


thyroidism prompted us to search for thyroid diseases in other patients with the same syndrome. We report herein five patients with $\mathrm{r}(18)$ syndrome and their thyroid finction.

\section{MATERIALS AND METHODS}

Five cases of $r(18)$ syndrome from three institutes were studied. The clinical data of these patients are summarized in Table 1. All the patients had typical clinical features of $r(18)$ syndrome. Three patients (Cases 1, 2 and 4) had a standard 45,XY or XX,r(18) karyotype, while the remaining two (Cases 3 and 5) had a mosaic 46,XY/46,XY,r(18) karyotype. High-resolution G-bandings revealed that the break points of the ring chromosomes in Cases 1, 2 and 4 were 18 p11.32 and 18q23 (Fig. 1). Cases 1 and 4 were clinically hypothyroid and required thyroxine therapy. Neonatal screening test for congenital hypothyroidism revealed normal in Cases 2 and 4 . Case 5 was one of the identical twins. The other twin was phenotypically normal, while he had a mosaic $46, \mathrm{XY} / 46, \mathrm{XY}, \mathrm{r}(18)$ karyotype in lymphocytes but a normal $46, \mathrm{XY}$ male karyotype in skin fibroblasts. These twins were previously reported by Hata et al. (1982).

Thyroid function was evaluated by measuring $T_{3}, T_{4}$ and TSH concentrations and by TRH test. Measurement of anti-thyroid antibody (ATA) titer and the histological study of thyroid tissue were also performed. ATA included thyroglobalin antibody and microsome antibody. Excessive TSH response in TRH test was judged on the basis of peak TSH concentration of $40 \mu \mathrm{U} / \mathrm{ml}$ or more. TRH test was performed in Cases 1,2 and 3. The thyroid tissue obtained by an open biopsy was histologically studied in Case 3. The levels of $\mathrm{T}_{3}, \mathrm{~T}_{4}, \mathrm{TSH}$ and ATA were also measured in the mothers of Cases 1 and 3 and the parents of Case 2.
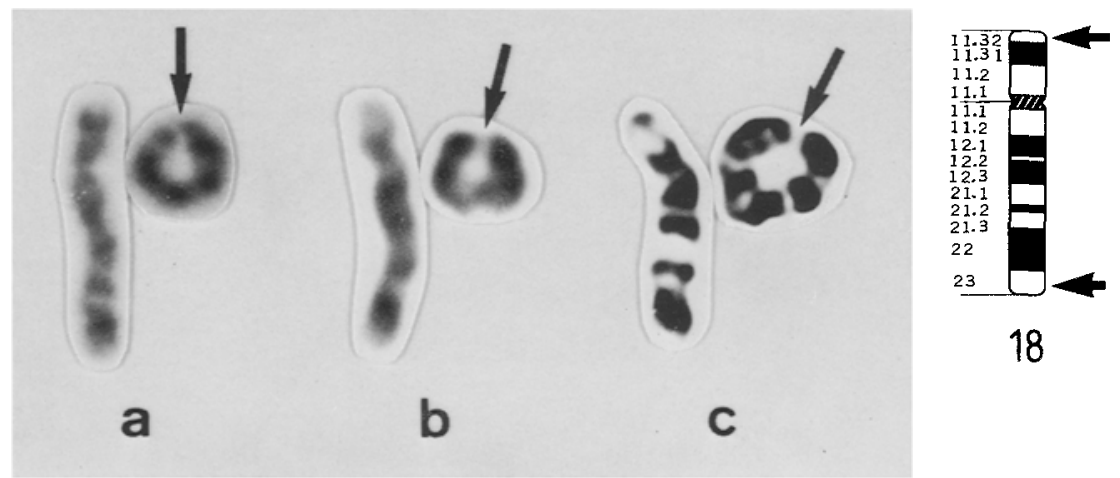

Fig. 1. High-resolution G-banded chromosome 18 from Case 1 (a), Case 2 (b) and Case 4 (c). Arrows on the chromosomes and on the ideogram show breakpoints, $18 \mathrm{p} 11.32$ and $18 \mathrm{q} 23$. 


\section{RESULTS}

The results are summarized in Table 1. Cases 1 and 4 had hypothyroidism. In Case $2, T_{3}$ and $T_{4}$ levels were within the normal range, but the basal TSH level was around the upper limits of the normal range and TRH test revealed an excessive TSH response, indicating primary hypothyroidism. Case 3 had a palpable goiter with the histology showing Hashimoto's thyroiditis (Fig. 2), although he was euthyroid and had a normal basal TSH level and a normal result of TRH test. Case 5 was euthyroid and the results of the tests were all normal. In the ATA study, microsome antibody was positive in Cases 1,2, 3 and 4, and thyroglobulin antibody was positive in Case 3 . These findings strongly suggest that all the patients but Case 5 suffer from autoimmune thyroiditis.

The mother of Case 2 had an elevated ATA titer and hypothyroidism detected by the following findings: $T_{3}$ was $0.9 \mathrm{ng} / \mathrm{ml}, \mathrm{T}_{4} 4.6 \mu \mathrm{g} / \mathrm{dl}$, TSH $16.8 \mu \mathrm{U} / \mathrm{ml}$ and thyroxine binding globulin $28 \mu \mathrm{g} / \mathrm{ml}$ (normal range: $11-27 \mu \mathrm{g} / \mathrm{ml}$ ). The mother of Case 3 had an elevated ATA titer but she was clinically and biochemically euthyroid. The mother of Case 1 and the father of Case 2 had normal results in these tests.

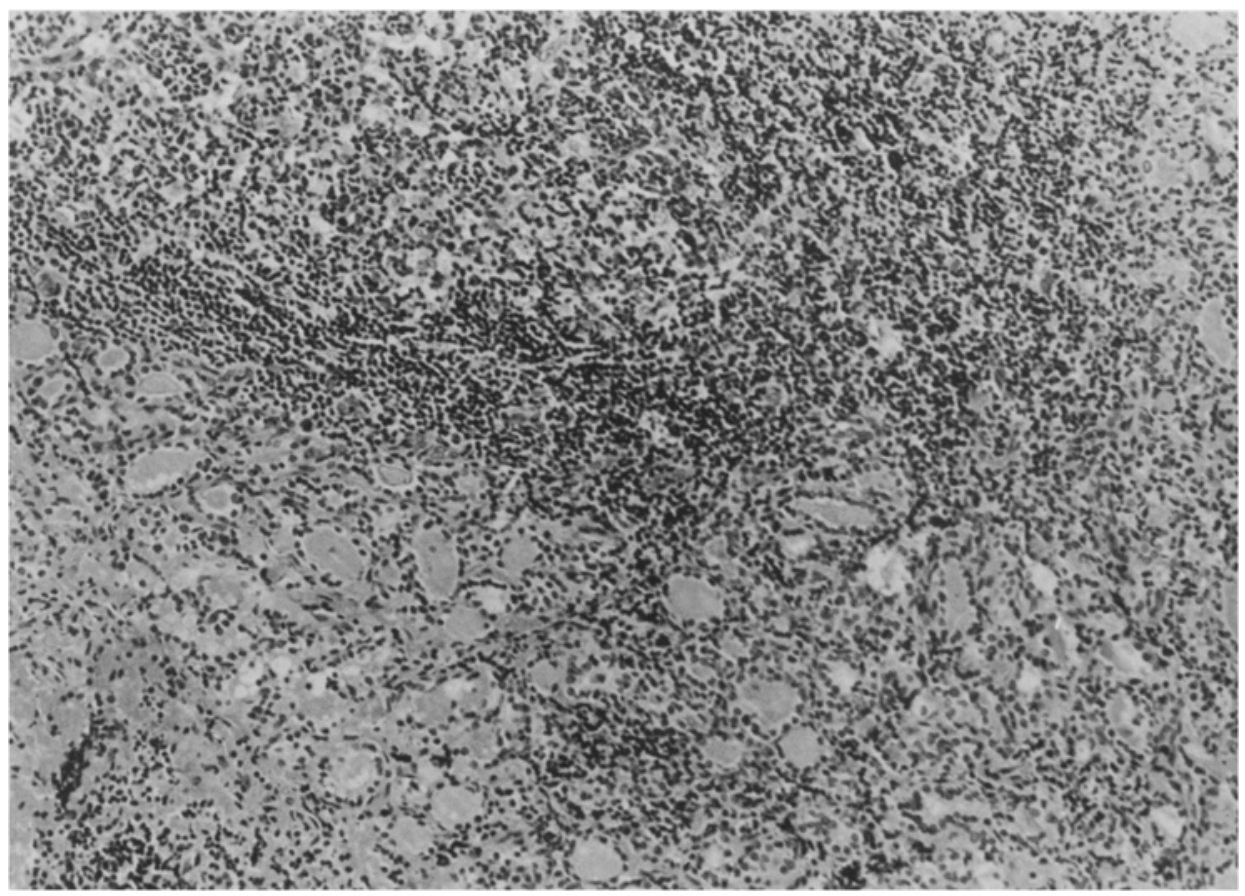

Fig. 2. Histology of thyroid tissue from Case 3 showed destruction of follicles, lymphocytic infiltration and oxyphilic cells which were compatible with Hashimoto's thyroiditis. 


\section{DISCUSSION}

The data presented in this paper strongly suggest that four of five patients with $r(18)$ syndrome examined have autoimmune thyroiditis. Since $r(18)$ syndrome is rare among the chromosomal abnormalities, its association with autoimmune thyroiditis in $80 \%$ of the patients is significant.

Previous studies have pointed out a relationship between chromosome 18 abnormalities and thyroid diseases. There have been six patients with $18 \mathrm{p}-$ syndrome associated with hypothyroidism (Bühler et al., 1964; Ruvalcava, 1970; Malpuech et al., 1971; Kistenmacher et al., 1973; Hasen and Bartalos, 1975; Gluckman, 1977), one 18p - patient with Graves disease (Jones and Carey, 1982), one 18qpatient with hypothyroidim (Faed et al., 1972), and one $\mathrm{r}(18)$ patient with hypothyroidism (Winter et al., 1972). Hypothyroidism in three of these six patients with $18 \mathrm{p}-$, as in our four patients, had been attributed to autoimmune thyroiditis. On the other hand, in the case with $r(18)$ syndrome described by Winter et al., an inborn error of thyroxine biosynthesis was postulated by the authors as a cause of the hypothyroidism, on the basis of negative thyroglobulin antibody. However, measurement of microsome antibody and histological study were not performed in this case. Thus, the possibility of the hypothyroidism due to autoimmune thyroiditis remained. With regard to autoimmune thyroiditis, it is generally known that the proportion of patients with positive thyroglobulin antibody is smaller than that of patients having microsome antibody.

The findings in our study, together with those in the previous studies, indicate that $r(18)$ syndrome is more frequently associated with autoimmune thyroiditis than $18 \mathrm{p}-$ or $18 \mathrm{q}-$ syndrome. It is most likely that the simultaneous lackings of the terminal segments of both the short and the long arms of a chromosome in $r(18)$ syndrome exert a synergistic effect on the occurrence of autoimmune thyroiditis.

The mechanism of the occurrence of hypothyroidism by the chromosome 18 abnormalities is obscure. IgA deficiency is frequently observed in $18 p-$ or $18 q-$ syndrome. A case of $18 \mathrm{q}-$ syndrome associated with absence of IgA and with hypothyroidism by Faed et al. (1972) may have suggested a pathogenic relationship of $\operatorname{IgA}$ deficiency and the occurrence of hypothyroidism. However, the relationship is less likely, because all of our patients but Case 1 were not complicated with IgA deficiency. Bühler (1983) recently proposed a mechanism of unmasking heterozygosity in order to explain an express of a recessive trait by balanced or unbalanced chromosomal aberrations. Hypothyroidism in $r(18)$ syndrome would be one of the examples, as ring chromosome 18 might cause the hemizygous state in regard to thyroiditis gene(s).

Mother of a patient with $\mathrm{r}(18)$ syndrome may have susceptibility to thyroid diseases. Two mothers of our patients (Cases 2 and 3) had an elevated ATA titer, one of whom (Case 2) was subclinically hypothyroid and required thyroxine therapy. 
The pathogenic relationship between the susceptibility to thyroid diseases in the mother and the occurrence of $\mathrm{r}(18)$ syndrome in the child remains obscure. In Down syndrome, it has been postulated that ATA or hypothyroidism in a mother may cause a non-disjunction (Fialkow et al., 1971). In the same way, the possibility remains that ATA or hypothyroidism in a mother have caused the ring formation during oogenesis in Case 2 with a non-mosaic $r(18)$ karyotype and during an early cleavage division of a zygote in Case 3 with a mosaic $r(18)$ karyotype. Further studies on additional cases are needed to draw a conclusion.

Acknowledgments We thank Dr. S. lizuka (Pediatric clinic, Hakodate Chuo Hospital) and Dr. H. Maesaka (Division of Endocrinology and Metabolism, Kanagawa Children's Medical Center) for their helpful advices. This study was supported in a part by Grant No. $82-0714$ from National Center for Nervous, Mental and Muscular Disorders of the Ministry of Health and Welfare, Japan.

\section{REFERENCES}

Bühler, E.M., Bühler, U.K., and Stalder, G.R. 1964. Partial monosomy 18 and anomaly of thyroxine synthesis. Lancet $\mathbf{i}: 170-171$.

Bühler, E.M. 1983. Unmasking of heterozygosity by inherited balanced translocations. Implication for prenatal diagnosis and gene mapping. Ann. Genet. 26: 133-137.

Faed, M.J.W., Whyte, R., Paterson, C.R., McCathie, M., and Robertson, J. 1972. Deletion of the long arms of chromosome $18(46, \mathrm{XX}, 18 \mathrm{q}-)$ associated with absence of IgA and hypothyroidism in an adult. J. Med. Genet. 9: 102-104.

Fialkow, P.J., Thuline, H.C., Hecht, F., and Bryant, J. 1971. Familial predisposition to thyroid disease in Down's syndrome: Controlled immunoclinical studies. Am. J. Hum. Genet. 23: $67-86$.

Gluckman, P.D. 1977. Autoimmune thyroiditis in a case of $18 \mathrm{p}-$ syndrome. Aust. Pediatr. J. 13: 122-124.

Hasen, J. and Bartalos, M. 1975. Dyshormonogenetic goitrous hypothyroidism in a patient with short arm deletion of E18 chromosome. Hormone Res. 6: 28-35.

Hata, A., Suzuki, Y., Matsui, I., and Kuroki, Y. 1982. Ring 18 mosaicism in identical twins. Hum. Genet, 62: 364-367.

Jones, K.L. and Carey, D.E. 1982. Graves disease in a patient with the del(18p) syndrome. Am. J. Med. Genet. 11: 449-452.

Kistenmacher, M.L., DiGeoge, A.M., and Punnett, H.H. 1973. The association of autoimmune disorders with $18 \mathrm{p}$ - syndrome. Am. J. Hum. Genet. 26: 49A.

Malpuech, G., Raynaud, E.J., Gaulme, J., and Godeneche, P. 1971. Complete deletion of the short arm of chromosome 18 and G18 translocation with dyschromy and hypothyroidism. Archs. fr. Pediatr. 28: 827.

Ruvalcaba, R.H.A. 1970. Deletion of chromosome group $\mathrm{E}$ and thyroid autoimmunity. $J$. Pediatr. 77: 343-344.

Winter, J.S.D., Ahluwalia, K., and Ray, M. 1972. Congenital hypothyroidism in association with a ring chromosome 18. J. Med. Genet. 9: 122-126. 